\title{
A translation and preliminary validation of the Dutch Wound-QoL questionnaire
}

Stella F. Amesz ${ }^{1 *+} \mathbb{D}$, Toni M. Klein ${ }^{2+}$, Audrey M. Meulendijks ${ }^{3}$, Tuong-Vi Nguyen ${ }^{4}$, Christine Blome ${ }^{2}$, Petrie F. Roodbol $\left.\right|^{5}$ and Catherine van Montfrans ${ }^{4}$

\begin{abstract}
Background: Chronic wounds have a major impact on patients' health-related quality of life (HRQoL). Therefore, measuring $\mathrm{HRQOL}$ is an indispensable part of the treatment of patients with chronic wounds. The aim of this study was to translate and validate the Wound-QoL, a wound-specific HRQoL questionnaire, in a Dutch population.

Methods: The Wound-QoL was translated into Dutch according to the international standards. Patients with chronic wounds were asked to complete questionnaires at baseline (TO) and after six weeks (T1), including WoundQoL, EQ-5D-3L (a generic questionnaire to measure HRQoL) and a visual analogue scale (VAS) measuring wound pain. If patients were not able to complete the questionnaire by themselves, it was read out to them by a nurse. Further data were obtained from medical records.

Results: Of the 120 patients included, 64 (53.3\%) completed the questionnaire by themselves. To 55 patients (45.8\%), the questionnaire was read out. The internal consistency of the Wound-QoL global score was high at both time points (T0: Cronbach's $a=0.89, \mathrm{T1}$ : Cronbach's $a=0.92$ ). The item selectivity for global score ranged from $r=$ 0.25 to $r=0.77$ at T0 and from $r=0.40$ to $r=0.79$ at T1. Overall, the self-completion and read-out subgroups showed similar internal consistency and item selectivity scores. With regard to convergent validity, significant correlations were found between Wound-QoL and EQ-5D-3L (TO: $r=-0.45, p<0.001, \mathrm{T1}: r=-0.50, p<0.001$ ) as well as between Wound-QoL and pain VAS (T0: $r=0.23, p=0.012$, T1: $r=0.37, p=0.001$ ) at both time points. Responsiveness analyses showed significant correlations between changes in Wound-QoL and changes in EQ-5D-3L $(r=-0.37, p<0.001)$, pain VAS $(r=0.24, p=0.044)$ and wound size $(r=0.24, p=0.013)$. The self-completion and read-out subgroups showed differences in convergent validity and responsiveness.
\end{abstract}

Conclusions: The results indicate that the Dutch version of the Wound-QoL has positive psychometric properties. However, more research is needed to further explore the differences between self-completed and read-out questionnaires.

Keywords: Chronic wounds, Validation, Dutch Wound-QoL questionnaire, Wound-QoL, EQ-5D-3L

\footnotetext{
* Correspondence: stellaamesz@gmail.com

${ }^{\dagger}$ Stella F. Amesz and Toni M. Klein contributed equally to this work.

${ }^{1}$ University of Groningen, Faculty of Medical Sciences, Kerkstraat 4, 8162RS

Epe, the Netherlands

Full list of author information is available at the end of the article
}

C C The Author(s). 2020 Open Access This article is licensed under a Creative Commons Attribution 4.0 International License, which permits use, sharing, adaptation, distribution and reproduction in any medium or format, as long as you give appropriate credit to the original author(s) and the source, provide a link to the Creative Commons licence, and indicate if changes were made. The images or other third party material in this article are included in the article's Creative Commons licence, unless indicated otherwise in a credit line to the material. If material is not included in the article's Creative Commons licence and your intended use is not permitted by statutory regulation or exceeds the permitted use, you will need to obtain permission directly from the copyright holder. To view a copy of this licence, visit http://creativecommons.org/licenses/by/4.0/ The Creative Commons Public Domain Dedication waiver (http://creativecommons.org/publicdomain/zero/1.0/) applies to the data made available in this article, unless otherwise stated in a credit line to the data. 


\section{Background}

Chronic wounds are lesions of the skin and subcutaneous tissue that show insufficient healing two to four weeks after occurrence according to the Dutch recommendation [1]. They may have various causes, such as venous or arterial insufficiency, diabetes mellitus, trauma, malignancy, self-mutilation or physical pressure [1]. A meta-analysis [2] including several worldwide studies showed a pooled prevalence of 2.21 per 1000 persons for chronic wounds of mixed aetiologies. A slightly higher annual prevalence of approximately 500, 000 patients was found in the Netherlands [3]. However, one must be careful not to compare prevalence rates with each other, because there is no uniform definition for the term 'chronic wound'. The prevalence of chronic wounds increases with age. The highest prevalence rates occur in people above the age of 65 [4]. Therefore, prevalence rates are likely to increase due to the ageing of the Dutch population [5].

Patients with chronic wounds often experience impairments such as pain, the necessity for frequent dressing changes and mobility limitation, which negatively impact the patients' health-related quality of life (HRQoL) [6, 7].

HRQoL is a multidimensional (e.g. physical, psychological, social) construct defined as the health-related functioning and well-being of a person [8]. Due to its subjectivity, HRQoL is assessed as patient-reported outcome (PRO). It is considered an important outcome measure of medical treatment in addition to the clinical outcome measures [9]. Nowadays, HRQoL questionnaires are widely used and play a major role in healthcare decisions and treatment evaluation [10]. The use of validated questionnaires to measure patient characteristics and treatment outcomes from the patients' perspective is necessary in the treatment of chronic wounds as well [11-13]. However, a validated, short, and easy-touse HRQoL questionnaire for clinical use is not available in the Netherlands.

In view of the age composition of the patient group with chronic wounds as well as the necessity to regularly assess HRQoL in routine care, brief and easy-to-use questionnaires are recommended [14].

For this purpose, the Wound-Qol questionnaire [12] has been developed based on three more extensive questionnaires for patients with wounds (the Cardiff Wound Impact Schedule (CWIS) [13], the Freiburg Life Quality Assessment for wounds (FLQA-W) [11] and the Wuerzburg Wound Score (WWS) [15]). The Wound-QoL [12, $15,16]$ consists of 17 questions from which a total scale score and three subscale scores can be calculated with higher values indicating worse HRQoL. The subscale 'body' is derived from items 1 to 5 (e.g., "my wound hurt", "the wound has affected my sleep"), the subscale "psyche" is derived from items 6 to 10 (e.g., "the wound has made me unhappy", "I have been afraid of knocking the wound"), and subscale 'everyday life' is derived from items 11 to 16 (e.g., "I have had trouble moving around because of the wound", "the wound has limited my leisure activities"). Item 17 does not belong to neither of the subscales. The Wound-QoL was developed to create a brief instrument. The Wound-QoL questionnaire has been translated into 20 languages (available on the website: www.wound-qol.com). However, a validated Dutch translation of the Wound-QoL has not yet become available.

Therefore, the aim of this study was to translate and validate the Wound-QoL questionnaire for Dutch people suffering from chronic wounds.

\section{Methods}

We translated the validated German Wound-QoL questionnaire into Dutch according to the international standards for cross-cultural adaptations of outcome instruments [17]. The translation process included two forward and two backward translations and harmonization of these versions.

In the pre-test, it became obvious that the Dutch version of the item "the wound has affected my sleep" did not suit the response scale. Therefore, slight alterations have been made so that this item keeps the same meaning but suits the response options better (from "kon ik door de wond niet goed slapen" to "had ik door de wond problemen met slapen"). Accordingly, the present study validated the Wound-QoL including this minor change.

In order to validate the Dutch version of the WoundQoL, we recruited patients with chronic wounds (of different aetiologies) who were able to speak and understand Dutch and were 18 years or older. Patients had to have a wound at both study inclusion and after six weeks. Only one exclusion criterion was defined (i.e., having a healed wound according the Dutch supported definition1 [1] of chronic wounds within the six weeks of study participation) to achieve a relatively heterogenous sample reflecting the target group of the Wound-QoL. Patients were recruited from a home care organization providing wound care for general practitioners and different wound centres in the Netherlands, which are part of both academic and non-academic hospitals. The aim was to recruit no fewer than 100 patients, which is considered an adequate sample size for analyzing various psychometric properties [18]. Recruitment took place from August 2018 to May 2019.

Patients were asked to complete the questionnaires during their visits at the moment of inclusion (T0) and after six weeks (T1). The first questionnaire consisted of sociodemographic questions (weight, height, number of people in the household), the Dutch version of the Wound-QoL, the generic HRQoL instrument EQ-5D-3L 
and a visual analogue scale (VAS) measuring the patients' worst pain during the day. The EQ-5D-3L is a short questionnaire assessing generic HRQoL using five questions about mobility, self-care, usual activities, pain, and anxiety/depression. Each question is answered on a three level scale representing no problems, some problems, and extreme problems. Additionally, the questionnaire encompasses a VAS about the patient's self-rated health [19]. The second questionnaire consisted of the same instruments except sociodemographic questions. Further data were obtained from medical records (age, gender, smoking habits, compression therapy, wound diagnosis, medication, comorbidities). Additionally, the size of the wound surface was measured at T0 and T1 by using a camera $\left(\operatorname{InSight}^{\circ}\right)$. For patients with various wounds, the size of the largest wound was measured.

The majority of patients completed the questionnaires by themselves (self-completion group). Other patients were also willing to answer the questionnaires but were not able or did not wish to complete the questionnaire by themselves. Reasons were, for example, that patients did not have their glasses with them or that it would burden them to read the questionnaires on their own. In these cases, nurses read out the questionnaires to the patients and ticked the according response options (read-out group).

For a small subgroup of participants, the time of completion was measured.

All patients gave prior written informed consent to participate in the study. The study has been approved by the medical ethical committee of the Isala Clinics (No. 180916; Zwolle, The Netherlands).

Statistical analyses were performed with SPSS Statistics version 25 (IBM $^{\circ}$, Armonk, NY). The Wound-QoL scores were calculated by averaging the respective items, if at least $75 \%$ of the items had been answered. The EQ$5 \mathrm{D}-3 \mathrm{~L}$ index was calculated by using the utility algorithm for the Netherlands. The following properties were analyzed in order to validate the Dutch Wound-QoL questionnaire: floor and ceiling effects (i.e. percentage of patients with the highest/lowest scores), internal consistency (i.e. Cronbach's alpha for the global scale and for each subscale), item selectivity (i.e. correlation of the global score with each item; correlation of the subscale scores with each respective item; correlation of the global score with the subscale scores), convergent validity (i.e. correlation of the global score with the EQ5D-3L score, score of pain VAS, the size of the wound surface), and responsiveness (i.e. correlation of changes between $\mathrm{T} 0$ to $\mathrm{T} 1$ in the global score with changes in the EQ-5D score, VAS score and the size of the wound surface). For convergent validity and responsiveness, a generic HRQoL has been chosen as other woundspecific questionnaires were not available in Dutch at the time of study conduct. To account for the specific burden posed by chronic wounds, wound pain and wound size have additionally been included as convergent criteria. Normal distribution of items and scores was tested using the one-sample Kolmogorov-Smirnov test. As Wound-QoL scores and items showed no normal distribution according to this test, non-parametric Spearman correlation was calculated. According to Cohen [20], a correlation coefficient will be interpreted as small when $r=0.1$, as moderate when $r=0.3$, and as large when $r=0.5$. For internal consistency, Cronbach's alpha of 0.7 can be considered acceptable and 0.9 can be considered good [21]. In order to account for possible bias caused by the different modes of completion (selfcompletion; read-out), we compared the sociodemographic aspects of both subgroups using unpaired t-test and Chi-squared tests, and we conducted each analysis in both the total sample and each subgroup.

For convergent validity, hypotheses were formulated about the direction and relative strength magnitude of the correlations between the Wound-QoL score comparator instruments. It was hypothesized that higher EQ-5D-3L scores would be associated with lower Wound-QoL scores, whereas higher pain VAS scores and larger wound size would be associated with higher Wound-QoL scores. With regard to the relative magnitude strength of the correlations, it was assumed that the correlation between Wound-QoL scores and EQ5D-3L scores were highest, because both instruments represent multidimensional HRQoL constructs. It was assumed that the correlation between Wound-QoL and pain VAS was the second strongest as pain is a major cause of limitation for patients [22]. The weakest correlation was expected to be found between WoundQoL and the wound size, as wound size itself does not cause major restrictions and burden compared to other aspects of the wound, such as pain or visibility. With regard to responsiveness, it was hypothesized that the directions and relative magnitudes of change in the instruments would correspond to those of convergent validity.

\section{Results}

We included 120 patients. Sixty-four of them (53.3\%) completed the questionnaire by themselves. To 55 of them $(45.8 \%)$, nurses read out the questionnaire. For one patient $(0.8 \%)$, there is no information about the mode of questionnaire completion. The gender distribution was almost equal ( $n=63,52.5 \%$ women). The patients had an average age of $73 \pm 14$ years $(\min =18, \max =98)$. On average, the wound size decreased from $9.88 \mathrm{~cm}^{2}$ at $\mathrm{T} 0$ to $6.84 \mathrm{~cm}^{2}$ at T1 (Table 1). The most common diagnoses (Table 2) were diabetic foot ulcer $(n=37,30.8 \%)$, venous ulcer $(n=20,16.7 \%)$ and ulcer caused by trauma 
Table 1 Sociodemographic and wound-specific descriptive statistics for the total sample and subsamples

\begin{tabular}{|c|c|c|c|c|c|c|c|}
\hline & \multicolumn{2}{|c|}{ Total sample $(\boldsymbol{N}=120)$} & \multicolumn{2}{|c|}{ Self-completion $(\boldsymbol{N}=64)$} & \multicolumn{2}{|c|}{ Read-out $(\boldsymbol{N}=55)$} & \multirow{2}{*}{$\begin{array}{l}\text { Self-completion vs. read-out } \\
\boldsymbol{p} \text {-value }{ }^{1}\end{array}$} \\
\hline & $\mathrm{n}$ & $\%$ & $\bar{n}$ & $\%$ & $\mathrm{n}$ & $\%$ & \\
\hline Male (vs. female) & 57 & 47.5 & 34 & 53.1 & 22 & 40.0 & 0.153 \\
\hline Smoker (yes) & 21 & 17.5 & 10 & 15.6 & 10 & 18.5 & 0.676 \\
\hline Living alone (yes) & 48 & 40.0 & 21 & 32.8 & 27 & 49.1 & 0.071 \\
\hline \multirow[t]{2}{*}{ Compression therapy (yes) } & 69 & 57.5 & 34 & 53.1 & 34 & 61.8 & 0.339 \\
\hline & $M$ & SD & $M$ & SD & $M$ & SD & $p$-value ${ }^{2}$ \\
\hline Age [years] & 73.23 & 14.24 & 68.89 & 14.71 & 78.42 & 11.99 & $<0.001$ \\
\hline Length [m] & 1.72 & 0.10 & 1.73 & 0.10 & 1.70 & 0.11 & 0.183 \\
\hline Weight [kg] & 82.52 & 19.85 & 84.36 & 17.03 & 80.00 & 22.79 & 0.238 \\
\hline BMI $\left[\mathrm{kg} / \mathrm{m}^{2}\right]$ & 27.75 & 5.48 & 28.11 & 4.74 & 27.30 & 6.33 & 0.427 \\
\hline Wound duration [weeks] & 34.55 & 65.02 & 22.28 & 39.61 & 49.50 & 84.43 & 0.023 \\
\hline Wound size at T0 $\left[\mathrm{cm}^{2}\right]$ & 9.88 & 21.33 & 9.39 & 13.69 & 10.57 & 27.89 & 0.766 \\
\hline Wound size at $\mathrm{T} 1\left[\mathrm{~cm}^{2}\right]$ & 6.84 & 18.67 & 7.33 & 15.05 & 6.36 & 22.42 & 0.786 \\
\hline Number of medications & 8.60 & 4.39 & 8.56 & 4.72 & 8.49 & 3.89 & 0.929 \\
\hline Number of comorbidities & 2.87 & 1.37 & 2.83 & 1.42 & 2.87 & 1.31 & 0.860 \\
\hline
\end{tabular}

${ }_{1}^{1} \mathrm{p}$-value according to Chi-squared tests, ${ }^{2} \mathrm{p}$-value according to unpaired t-test

Table 2 Wound diagnoses and comorbidities at baseline

\begin{tabular}{|c|c|c|}
\hline & Frequency & Percentage \\
\hline \multicolumn{3}{|l|}{ Wound diagnoses } \\
\hline Diabetic foot ulcer & 37 & 30.8 \\
\hline Venous ulcer & 20 & 16.7 \\
\hline Traumatic ulcer & 19 & 15.8 \\
\hline Arterial ulcer & 14 & 11.7 \\
\hline Malignant ulcer & 8 & 6.7 \\
\hline Mixed ulcer & 6 & 5.0 \\
\hline Pressure ulcer & 5 & 4.2 \\
\hline Vasculitis & 1 & 0.8 \\
\hline Other & 10 & 8.3 \\
\hline \multicolumn{3}{|l|}{ Comorbidities $^{\mathrm{a}}$} \\
\hline Cardiovascular diseases & 81 & 67.5 \\
\hline Diabetes & 58 & 48.3 \\
\hline Peripheral vascualar diseases & 53 & 44.2 \\
\hline Chronic obstructive pulmonary disease & 26 & 21.7 \\
\hline Rheumatism & 25 & 20.8 \\
\hline Renal failure & 21 & 17.5 \\
\hline Oncologic disease & 17 & 14.2 \\
\hline Thrombosis/pulmonary embolism & 14 & 11.7 \\
\hline Surgical intervention & 13 & 10.8 \\
\hline Neurological disorders & 11 & 9.2 \\
\hline Thyroid disorders & 10 & 8.3 \\
\hline Psychiatric disorders & 8 & 6.7 \\
\hline Other & 12 & 10.0 \\
\hline
\end{tabular}

apercentages do not sum up to $100.0 \%$ because multiple answers were possible
( $n=19,15.8 \%)$. The majority of wounds were located on the lower legs $(n=61,50.8 \%)$ and feet $(n=48,40.0 \%)$. The most frequent comorbidities (Table 2) were cardiovascular diseases $(n=81,67.5 \%)$, diabetes $(n=58,48.3 \%)$ and peripheral vascular diseases $(n=53,44.2 \%)$.

Descriptive statistics of the Wound-QoL items, the global scale, and the subscale can be seen in Table 3.

\section{Number of missing values}

Of the 17 items, nine items at T0 and eight items at T1 showed no missing values. One item ("climbing stairs has been difficult because of the wound') showed a large number of missing values (T0: 29.2\%, T1: 25.0\%). All patients with missing values for this item filled in or stated during the interview that this item was not applicable to their situation, but this was not a response option in the Wound-QoL. For the remaining items, the number of missing values ranged from 0.8 to $2.5 \%$ at both time points equalling to one to three patients per item. Regarding the global and subscale scores, only for one patient at T0 and three patients at T1 the subscale 'everyday life' could not be calculated because of too many missing values.

\section{Floor and ceiling effects}

The global score showed no ceiling effect at either time point and a minor floor effect only at $\mathrm{T} 1(0.8 \%)$. Although the 'body' and 'psyche' subscales did not show ceiling effects at T0, the 'psyche' subscale showed a minor ceiling effect at T1 (0.8\%). The 'everyday life' subscale showed minor ceiling effects at both time points (T0: 1.7\%, T1: 3.4\%). All subscales showed floor effects 
Table 3 Descriptive statistics of Wound-QoL items, global scale, and subscales at the first and second visit

\begin{tabular}{|c|c|c|c|c|c|c|c|c|c|c|c|}
\hline \multicolumn{2}{|c|}{ Wound-QoL items and scales } & \multicolumn{5}{|l|}{ T0 } & \multicolumn{5}{|l|}{$\mathrm{T} 1$} \\
\hline & In the last seven days ... & $\mathrm{n}$ & $\min$ & $\max$ & mean & SD & $\mathrm{n}$ & $\min$ & $\max$ & mean & SD \\
\hline 1 & my wound hurt & 120 & 0.00 & 4.00 & 1.51 & 1.230 & 119 & 0.00 & 4.00 & 1.35 & 1.266 \\
\hline 2 & my wound had a bad smell & 119 & 0.00 & 4.00 & 0.34 & 0.807 & 120 & 0.00 & 4.00 & 0.29 & 0.782 \\
\hline 3 & the discharge from the wound has upset me & 119 & 0.00 & 4.00 & 0.90 & 1.182 & 120 & 0.00 & 4.00 & 0.73 & 1.075 \\
\hline 4 & the wound has affected my sleep & 120 & 0.00 & 4.00 & 1.18 & 1.288 & 118 & 0.00 & 4.00 & 0.86 & 1.233 \\
\hline 5 & the treatment of the wound has been a burden to me & 118 & 0.00 & 4.00 & 0.92 & 1.207 & 118 & 0.00 & 4.00 & 0.82 & 1.159 \\
\hline 6 & the wound has made me unhappy & 118 & 0.00 & 4.00 & 0.93 & 1.238 & 120 & 0.00 & 4.00 & 0.80 & 1.149 \\
\hline 7 & I have felt frustrated because the wound is taking so long to heal & 120 & 0.00 & 4.00 & 1.58 & 1.406 & 120 & 0.00 & 4.00 & 1.72 & 1.379 \\
\hline 8 & I have worried about my wound & 119 & 0.00 & 4.00 & 1.42 & 1.453 & 118 & 0.00 & 4.00 & 1.27 & 1.400 \\
\hline 9 & I have been afraid of the wound getting worse or of getting new wounds & 120 & 0.00 & 4.00 & 1.36 & 1.431 & 120 & 0.00 & 4.00 & 1.21 & 1.289 \\
\hline 10 & I have been afraid of hitting the wound against something & 119 & 0.00 & 4.00 & 1.61 & 1.445 & 119 & 0.00 & 4.00 & 1.34 & 1.337 \\
\hline 11 & I have had trouble moving around because of the wound & 117 & 0.00 & 4.00 & 1.50 & 1.362 & 117 & 0.00 & 4.00 & 1.23 & 1.373 \\
\hline 12 & climbing stairs has been difficult because of the wound & 85 & 0.00 & 4.00 & 1.47 & 1.385 & 90 & 0.00 & 4.00 & 1.13 & 1.400 \\
\hline 13 & I have had trouble with everyday activities because of the wound & 120 & 0.00 & 4.00 & 1.55 & 1.466 & 120 & 0.00 & 4.00 & 1.23 & 1.288 \\
\hline 14 & the wound has limited my recreational activities & 120 & 0.00 & 4.00 & 1.74 & 1.520 & 120 & 0.00 & 4.00 & 1.49 & 1.402 \\
\hline 15 & the wound has forced me to limit my contact with other people & 120 & 0.00 & 4.00 & 1.64 & 1.549 & 118 & 0.00 & 4.00 & 1.47 & 1.424 \\
\hline 16 & I have felt dependent on help from others because of the wound & 120 & 0.00 & 4.00 & 1.80 & 1.447 & 120 & 0.00 & 4.00 & 1.52 & 1.372 \\
\hline 17 & the wound has been a financial burden to me & 120 & 0.00 & 4.00 & 0.62 & 1.161 & 119 & 0.00 & 4.00 & 0.48 & 0.910 \\
\hline \multicolumn{2}{|c|}{ Global score } & 120 & 0.06 & 3.35 & 1.29 & 0.788 & 120 & 0.00 & 3.24 & 1.12 & 0.785 \\
\hline \multicolumn{2}{|c|}{ Subscale 'body' } & 120 & 0.00 & 3.60 & 0.98 & 0.765 & 120 & 0.00 & 3.00 & 0.81 & 0.748 \\
\hline \multicolumn{2}{|c|}{ Subscale 'psyche' } & 120 & 0.00 & 3.80 & 1.38 & 1.031 & 120 & 0.00 & 4.00 & 1.27 & 0.987 \\
\hline \multicolumn{2}{|c|}{ Subscale 'everyday life' } & 119 & 0.00 & 4.00 & 1.62 & 1.213 & 117 & 0.00 & 4.00 & 1.36 & 1.131 \\
\hline
\end{tabular}

TO first visit, $T 1$ second visit, $N$ number of patients completing the item/for whom the respective scale could be calculated, min minimum, max maximum, $S D$ standard deviation

at both T0 (body: 12.5\%, psyche: 9.2\%, everyday life: $6.7 \%)$ and $\mathrm{T} 1$ (21.7, 7.5, 11.1\% respectively). Floor effects in 'body' and 'everyday life' subscales were less pronounced in the patients who completed the questionnaire by themselves (T0: 6.3, 4.7\%, T1: 18.8, 8.1\% respectively) compared to the patients in the read-out group (T0: 20.0, 9.3\%, T1: 25.5, 14.8\% respectively).

\section{Changes in the mean scores}

The mean values decreased over time for both WoundQoL global score (T0: 1.29, T1: 1.12) and Wound-QoL subscale scores (body: T0: 0.98, T1: 0.81, psyche: T0: 1.38, T1: 1.27 , everyday life: T0: 1.59 , T1: 1.36 ). The $\mathrm{t}-$ test results revealed significant improvements for the global score $(\mathrm{t}(119)=2.566, p=0.012)$, the 'body' subscale ( $\mathrm{t}(119)=2.221, p=0.028)$ and the 'everyday life' subscale ( $\mathrm{t}(119)=2.500, p=0.014)$, but not for the 'psyche' subscale (t $(119)=1.136, p=0.258)$.

When we consider each of the subgroups, a significant change was observed in the self-completion group (global score: $p=0.005$, body: $p=0.038$, everyday life: $p=0.002$, psyche: $p=0.076$ ), but not in the read-out group (global score: $p=0.820$, body: $p=0.371$, everyday life: $p=0.783$, psyche: $p=0.404$ ).

\section{Internal consistency}

The internal consistency of the Wound-QoL global score was high at both times points (T0: $\alpha=0.889$, T1: $\alpha=0.918)$. With regard to the subscales, the internal consistency was highest for the 'everyday life' subscale (T0: $\alpha=0.895, \mathrm{~T} 1: \alpha=0.925)$, followed by the 'psyche' subscale (T0: $\alpha=0.794, \mathrm{~T} 1: \alpha=0.811$ ) and the 'body' subscale (T0: $\alpha=0.673, \quad \mathrm{~T} 1: \alpha=0.687$ ). The selfcompleted and read-out questionnaires showed the same patterns.

\section{Item selectivity}

The item selectivity of the items of the global score ranged from $r=0.251$ to $r=0.768$ at T0 and from $r=$ 0.395 to $r=0.793$ at $\mathrm{T} 1$. The items with the highest correlation coefficients were: 'I have had trouble with everyday activities because of the wound' (T0: $r=0.768$, T1: $r=0.793)$, 'the wound has limited my recreational activities' (T0: $r=0.760, \mathrm{~T} 1: \mathrm{r}=0.723$ ), 'the wound has forced me to limit my contact with other people' (T0: $\mathrm{r}=0.754, \mathrm{~T} 1: \mathrm{r}=0.727$ ) and 'I have had trouble moving around because of the wound' (T0: $r=0.712, \mathrm{~T} 1: \mathrm{r}=$ 0.728). It should also be noted that these four items 
showed the highest correlation coefficients in both the self-completion and the read-out group.

The item selectivity for the 'body' subscale ranged from $r=0.369$ to $r=0.769$ at $\mathrm{T} 0$ and from $r=0.515$ to $\mathrm{r}=0.775$ at $\mathrm{T} 1$; for the 'psyche' subscale, it ranged from $\mathrm{r}=0.677$ to $\mathrm{r}=0.778$ at $\mathrm{T} 0$ and from $\mathrm{r}=0.593$ to $\mathrm{r}=$ 0.807 at $\mathrm{T} 1$ and for the 'everyday life' subscale, it ranged from $r=0.703$ to $r=0.890$ at $\mathrm{T} 0$ and from $r=0.707$ to $\mathrm{r}=0.870$ at $\mathrm{T} 1$. The correlation between the global scale and subscales was highest for the 'everyday life' subscale (T0: $r=0.867, \mathrm{~T} 1: \mathrm{r}=0.874$ ), followed by the 'psyche' subscale (T0: $r=0.801, \mathrm{~T} 1: \mathrm{r}=0.801$ ) and the 'body' subscale (T0: $r=0.632, \mathrm{~T} 1: \mathrm{r}=0.689$ ).

Item selectivity generally showed minor effects and was similar for both the self-completion and the readout subgroup.

\section{Convergent validity}

The correlation between EQ-5D-3L and Wound-QoL was significant (T0: $\mathrm{r}=-0.451, p<0.001, \mathrm{~T} 1: \mathrm{r}=-0.501$, $p<0.001)$. The same accounts for the correlation between pain VAS and Wound-QoL (T0: $\mathrm{r}=0.232, p=$ $0.012, \mathrm{~T} 1: \mathrm{r}=0.372, p=0.001$ ). Although the correlation between the wound size and Wound-QoL was significant at $\mathrm{T} 1(\mathrm{r}=0.228, p=0.015)$, it was not significant at T0 $(r=0.124, p=0.178)$. These correlations with the EQ-5D-3L represent moderate to large effect sizes, whereas the other correlations represent small to moderate effect sizes [20].

For the self-completion subgroup, the correlation between EQ-5D-3L and Wound-QoL was significant at both time points (T0: $\mathrm{r}=-0.611, p<0.001, \mathrm{~T} 1: \mathrm{r}=-$ $0.501, p<0.001)$. For the read-out subgroup, the correlation between EQ-5D-3L and Wound-QoL was significant at both time points as well (T0: $\mathrm{r}=-0.306$, $p=0.023, \mathrm{~T} 1 \mathrm{r}=-0.556, p<0.001)$. Additionally, for the read-out subgroup, the correlation between pain VAS and Wound-QoL was significant at both time points (T0: $\mathrm{r}=0.357, p=0.008$, T1: $\mathrm{r}=0.486, p=0.003$ ). The correlations with the EQ-5D-3L again represent moderate to large effect sizes, whereas the correlations with the pain VAS represent moderate effect sizes [20]. Table 4 shows the results regarding convergent validity for the total group and the subgroups.

\section{Responsiveness}

Significant correlations were found between changes in Wound-QoL and changes in EQ-5D-3L $(r=-0.373, p<$ $0.001)$, changes in pain VAS $(r=0.239, p=0.044)$ and changes in wound size $(\mathrm{r}=0.235, p=0.013)$. Although the effect sizes were moderate for correlations between changes in Wound-QoL and changes in EQ-5D-3L, the effect sizes were small for the correlations between changes in Wound-QoL and changes in pain VAS and wound size.
Table 4 Convergent validity of the Wound-QoL global score

\begin{tabular}{|c|c|c|c|c|c|c|}
\hline & \multicolumn{2}{|c|}{ EQ-5D-3L } & \multicolumn{2}{|c|}{ Pain VAS } & \multicolumn{2}{|c|}{ Wound size } \\
\hline & TO & $\mathrm{T} 1$ & TO & $\mathrm{T} 1$ & T0 & $\mathrm{T1}$ \\
\hline \multicolumn{7}{|c|}{ Total sample } \\
\hline r & -0.451 & -0.501 & 0.232 & 0.372 & 0.124 & 0.228 \\
\hline$p$-value & $<0.001$ & $<0.001$ & 0.012 & 0.001 & 0.178 & 0.015 \\
\hline$n$ & 119 & 119 & 116 & 75 & 119 & 113 \\
\hline \multicolumn{7}{|c|}{ Subgroup: Self-completion } \\
\hline r & -0.611 & -0.501 & 0.180 & 0.306 & 0.143 & 0.242 \\
\hline$p$-value & $<0.001$ & $<0.001$ & 0.165 & 0.055 & 0.263 & 0.063 \\
\hline $\mathrm{n}$ & 63 & 64 & 61 & 40 & 63 & 60 \\
\hline \multicolumn{7}{|c|}{ Subgroup: Read-out } \\
\hline r & -0.306 & -0.556 & 0.357 & 0.486 & 0.032 & 0.212 \\
\hline$p$-value & 0.023 & $<0.001$ & 0.008 & 0.003 & 0.816 & 0.132 \\
\hline $\mathrm{n}$ & 55 & 54 & 54 & 35 & 55 & 52 \\
\hline
\end{tabular}

Significant results are marked bold; $r$ Spearman correlation coefficient, $n$ number of patients, VAS visual analogue scale

For the self-completion subgroup, only the correlation between changes in Wound-QoL and changes in EQ-5D$3 \mathrm{~L}$ was significant $(r=-0.408, p=0.001)$. The effect size was moderate. For the read-out subgroup, the correlation between changes in Wound-QoL and changes in EQ-5D$3 \mathrm{~L}(\mathrm{r}=-0.285, p=0.037)$, as well as the correlation between changes in Wound-QoL and changes in wound size $(r=0.290, r=0.037)$, were significant, each representing small effect sizes. Table 5 shows the results regarding responsiveness for the total sample and the subgroups.

\section{Time of completion}

For nine patients, the time needed to complete the Wound-QoL questionnaire was recorded. The time

Table 5 Responsiveness of the Wound-QoL global score

\begin{tabular}{llll}
\hline & EQ-5D-3L & Pain VAS & Wound size \\
\hline Total sample & & & \\
$r$ & $-\mathbf{0 . 3 7 3}$ & $\mathbf{0 . 2 3 9}$ & $\mathbf{0 . 2 3 5}$ \\
p-value & $<\mathbf{0 . 0 0 1}$ & $\mathbf{0 . 0 4 4}$ & $\mathbf{0 . 0 1 3}$ \\
$\mathrm{N}$ & $\mathbf{1 1 8}$ & $\mathbf{7 1}$ & $\mathbf{1 1 2}$ \\
Subgroup: self-completing & & \\
r & $\mathbf{- 0 . 4 0 8}$ & 0.293 & 0.184 \\
p-value & $\mathbf{0 . 0 0 1}$ & 0.078 & 0.162 \\
N & $\mathbf{6 3}$ & 37 & 59 \\
Subgroup: read-out & & & \\
r & $\mathbf{- 0 . 2 8 5}$ & 0.154 & $\mathbf{0 . 2 9 0}$ \\
p-value & $\mathbf{0 . 0 3 7}$ & 0.383 & $\mathbf{0 . 0 3 7}$ \\
n & $\mathbf{5 4}$ & 34 & $\mathbf{5 2}$ \\
\hline
\end{tabular}

Significant results are marked bold; $r$ Spearman correlation coefficient, $n$ number of patients, VAS visual analogue scale 
needed ranged from 0:57 min (self-completion) to 3:53 min (read out) at T0.

\section{Discussion}

The aim of this study was to translate the Wound-QoL questionnaire into Dutch and to test the validity of the translated version. Overall, the results showed that the Dutch version of the Wound-QoL is a valid instrument that only takes little time to complete. It showed a good internal consistency and a small to moderate yet significant convergent validity with the EQ-5D-3L for the total sample. These results are similar to those from the validation study of the Swedish Wound-QoL [23]. Additionally, the results of the present study are similar with the results regarding the German original version [24].

Similar to previous studies [23], only the item about 'climbing stairs' showed a high number of missing values. Patients who completed the questionnaire by themselves often added a comment next to this item. Patients to whom the questionnaire was read out expressed during the interview with a nurse that this item did not apply to them (e.g. because climbing the stairs was not part of their daily routine). However, further analyses (not shown in the results section) revealed that the exclusion of this item would not impact the overall results.

For convergent validity and responsiveness analyses, other Dutch wound-specific questionnaires were not available at the time of the study conduct. Therefore, a generic HRQoL instrument (EQ-5D-3L) and woundspecific clinical data were used. Overall, formulated hypotheses were confirmed. Significant yet moderate correlations between Wound-QoL and the pain VAS show that wound pain is not the only wound characteristic influencing disease-specific HRQoL. Here it needs to be considered that pain might not only be caused by the wound itself but also by wound-related factors, such as wound dressing [25]. The Wound-QoL does not differentiate between different sources of pain. If patients report high impairment in the pain item (or in fact, in any item), it is important to discuss the nature of impairments with the individual patient in order to optimize wound care [26]. Stronger correlations between generic and wound-specific HRQoL show that both types of HRQoL adequately reflect an overall picture of the patient's situation. However, differences between these constructs underlined that the generic HRQoL is influenced by other aspects than the wound as well. Additionally, convergent validity analyses showed no significant correlation between Wound-QoL and wound size. This could mean that the physical impact (e.g. pain, odour) and the visible impact (e.g. exudate) of a wound is more burdensome than the wound size itself [15]. However, improvements in any of these characteristics (generic HRQoL, pain, wound size) were correlated with improvements in the wound-specific HRQoL according to the Wound-QoL.

For several psychometric properties, we observed differences between the patients who completed the questionnaire by themselves and those to whom the questionnaire was read out. With regard to floor effects, change in mean scores, convergent validity and responsiveness in particular, discrepancies were found between the two subgroups. The sample characteristics showed that the patients in the read-out subgroup were significantly older and had wounds of longer duration than the other subgroup. Especially, the longer wound duration in the read-out group might explain the absence of significant HRQoL change in this group, because the longer a wound persists the more likely is that it is a particularly hard-to-heal wound that is less likely to show improvement. An alternative explanation may be that patients with shorter wound duration are still adapting to the situation, which can improve their HRQoL [27]. Overall, it cannot be decided whether the mode of completion changed the validity of the questionnaire or whether structural differences between the two subgroups were causing these discrepancies. This could be investigated in future studies, in which a patient sample is randomized into a self-completion and a read-out group. In order to minimize this potential bias when using the Wound-QoL, read-out completion should be as similar to self-completion as possible by closely sticking to the questionnaire text. If possible, individual patients should use the same mode every time they complete the questionnaire in order to ensure comparability over time.

Finally, it should be noted that this validation study analyzed psychometric properties of the total scale and subscales, which serves research and evaluation purposes in particular. However, we recommend that the patients' responses are considered on an item level for routine care purposes as well as each aspect can be of great importance for individuals [7]. Therefore, the patients' responses to items about physical burden (e.g. odour, exudate), emotional burden (e.g. frustration, worries) and limitations in activities of daily living (e.g. leisure activities, contact with others) should be considered for shared decision-making and joint goal setting.

One of the strengths of this study is that we reached the targeted size of the total sample and each subgroup (self-completion and read-out) consisted of more than 50 patients, representing a good sample size for analysing psychometric properties [18]. At the time of study conduction, no other wound-specific HRQoL questionnaire had been translated into Dutch. In the meanwhile, the CWIS had been translated into and validated in Dutch [28]. However, this is a comparably long questionnaires and the authors of the Dutch CWIS study 
mention the necessity of a short instrument. Accordingly, this was the first translation and validation of a short and easy-to-use Dutch HRQoL questionnaire, which is promising for future clinical care and research.

A limitation of this study is the phrasing of one item ("the wound has affected my sleep") being slightly changed in order to better fit the response options. Therefore, the present Dutch version of the WoundQoL slightly differed from the standardized translation process [29]. Another limitation was that time of completion was measured for only a small subgroup of patients. As some patients expressed to feel under time pressure when we took their time of completion, we decided to stop time measurement because this was not a primary research question. The most frequent wound aetiology were diabetic foot ulcers, despite venous leg ulcers being the most prevalent aetiology in Western countries. This was caused by the fact that enrolled patients were treated by a vascular surgeon, whereas patients with venous leg ulcers are more often treated by dermatologists in the Netherlands. As HRQoL and pain might differ with regard to the underlying aetiology, this might lead to some deviations from patients in other settings [25].

Overall, this study indicates that the Dutch WoundQoL questionnaire is a valid instrument for measuring the HRQoL of patients with chronic wounds. However, the study also shows different outcomes between selfcompleted and read-out questionnaires. In further studies, the validity of different modes of questionnaire completion should be investigated. Furthermore, this should raise awareness about new modes of questionnaire completion for people who are not able to complete questionnaires themselves.

\section{Conclusions}

The results indicate that the Dutch version of the Wound-QoL has positive psychometric properties. However, more research is needed to further explore the differences between self-completed and read-out questionnaires.

\section{Abbreviations \\ CWIS: Cardiff Wound Impact Schedule; FLQA-W: Freiburg Life Quality Assessment for wounds; HRQoL: Health-related quality of life; n: number of patients; PRO: Patient-reported outcome; p: significance level; r: Spearman correlation coefficient; T0 : Patients were asked to complete the questionnaires during their visits at the moment of inclusion; T1 : Patients were asked to complete the questionnaires during their visits after six weeks; VAS: Visual analogue scale; WWS: The Wuerzburg Wound Score}

\section{Acknowledgements}

Not applicable.

\section{Authors' contributions}

SA has collected data for the study, has interpreted the data and has drafted major parts of the work. TK has conducted analysis of data, has interpreted the data, and has drafted major parts of the work and revised it. AM has conducted additional analysis and interpretation of data and revised the manuscript. TN has made a substantial contribution by performing the translation process of the original Wound-QoL. CB has interpreted data and revised the work. PR has supervised the process from conception to writing of the manuscript. CM has made major contribution to the design of the study, has interpreted data, and has revised the work. The language centre of the University of Groningen has corrected the manuscript with regard to the English language. The author(s) read and approved the final manuscript.

\section{Funding}

This research received no specific grant from any funding agency in the public, commercial, or not-for-profit sectors. Publication of this article is funded by the corresponding author.

Availability of data and materials

On request from corresponding author.

\section{Ethics approval and consent to participate}

All patients gave prior written informed consent to participate in the study. The study has been approved by the medical ethical committee of the Isala Clinics (No. 180916; Zwolle, The Netherlands).

Consent for publication

Not applicable.

\section{Competing interests}

The authors declare that they have no conflict of interest.

\section{Author details}

'University of Groningen, Faculty of Medical Sciences, Kerkstraat 4, 8162RS Epe, the Netherlands. ${ }^{2}$ German Centre for Health Services Research in Dermatology (CVderm), Institute for Health Services Research in Dermatology and Nursing (IVDP), University Medical Center Hamburg-Eppendorf, Hamburg, Germany. ${ }^{3}$ Research Group Healthy and Sustainable Living, HU University of Applied Sciences, Utrecht, the Netherlands. ${ }^{4}$ Department of Dermatology, Erasmus University Medical Center, Rotterdam, The Netherlands. ${ }^{5}$ University of Groningen, University Medical Center Groningen, Groningen, The Netherlands.

Received: 21 April 2020 Accepted: 10 August 2020

Published online: 26 August 2020

\section{References}

1. Wondplatform Kwaliteitsstandaard Organisatie van wondzorg in Nederland 2018, available at: https:www.wcs.nl/wp-content/uploads/ kwaliteitsstandaard-Organisatie-van-wondzorg-in-Nederland.pdf (last accessed on 10 September 2018).

2. Martinengo L, Olsson M, Bajpai R, Soljak M, Upton Z, Schmidtchen A, et al. Prevalence of chronic wounds in the general population: systematic review and meta-analysis of observational studies. Ann Epidemiol. 2019:29:8-15.

3. Nederlandse Zorgautoriteit. Rapport Innovatie van complexe wondzorg 2014. Available at: https://puc.overheid.nl/nza/doc/PUC_3196_22/1/ (last accessed on 10 September 2018)

4. Amesz S, Monsma M, Corporaal G, Oskam J. Betere wondzorg; 2018.

5. Stoeldraijer L, Van Duin C, Huisman C. CBS - Bevolkingsprognose 20172060: 18,4 miljoen inwoners in 2060. CBS - Stat Trends. 2017;19:10.

6. Olsson M, Järbrink K, Divakar U, Bajpai R, Upton Z, Schmidtchen A, et al. The humanistic and economic burden of chronic wounds: a systematic review. Wound Repair Regen. 2019:27(1):114-25.

7. Augustin M, Blome C, Zschocke I, Schäfer I, Koenig S, Rustenbach SJ, et al. Benefit evaluation in the therapy of chronic wounds from the patients' perspective-development and validation of a new method. Wound Repair Regen. 2012;20(1):8-14.

8. Bullinger M. Assessing health related quality of life in medicine. An overview over concepts, methods and applications in international research. Restor Neurol Neurosci. 2002;20(3-4):93-101.

9. Wukich DK, Raspovic KM. Assessing health-related quality of life in patients with diabetic foot disease: why is it important and how can we improve? The 2017 Roger E. Pecoraro award lecture. Diabetes Care. 2018;41(3):391-7.

10. Wouters E, Canters N. Kwaliteit van leven. Den Haag: Boom Lemma uitgevers; 2011. p. 1-175. 
11. Augustin M, Herberger K, Rustenbach SJ, Schäfer I, Zschocke I, Blome C. Quality of life evaluation in wounds: validation of the Freiburg life quality assessment-wound module, a disease-specific instrument*. Int Wound J. 2010;7(6):493-501.

12. Blome C, Baade K, Debus ES, Price P, Augustin M. The " wound-QoL ": a short questionnaire measuring quality of life in patients with chronic wounds based on three established disease-specific instruments. WoundRepair Regen. 2014;22(4):504-14.

13. Price P, Harding K. Cardiff wound impact schedule: the development of a condition-specific questionnaire to assess health-related quality of life in patients with chronic wounds of the lower limb. Int Wound J. 2004; (1):10-7.

14. Hickey A, Barker M, McGee H, O'Boyle C. Measuring health-related quality of life in older patient populations: a review of current approaches. Pharmacoeconomics. 2005;23(10):971-93.

15. Engelhardt $\mathrm{M}$, Spech $\mathrm{E}$, Diener $\mathrm{H}$, Faller $\mathrm{H}$, Augustin $\mathrm{M}$, Debus ES. Validation of the disease-specific quality of life Wuerzburg wound score in patients with chronic leg ulcer. Vasa. 2014;43(5):372-9.

16. Sommer R, Augustin M, Hampel-Kalthoff C, Blome C. The wound-QoL questionnaire on quality of life in chronic wounds is highly reliable. Wound Repair Regen. 2017;25(4):730-2.

17. Epstein J, Santo RM, Guillemin F. A review of guidelines for cross-cultural adaptation of questionnaires could not bring out a consensus. J Clin Epidemiol. 2015;68(4):435-41.

18. Mokkink LB, Terwee $C B$, Gibbons $E$, et al. Inter-rater agreement and reliability of the COSMIN (Consensus-based Standards for the selection of health status Measurement Instruments) checklist. BMC Med Res Methodol. 2010;10:82 Published 2010 Sep 22. https://doi.org/10.1186/1471-2288-10-82 .

19. van Reenen M, Janssen B. EQ-5D User Guides - EQ-5D. EuroQOL Res Foundation. 2015; Available from: https:/euroqol.org/publications/userguides/. Accessed 14 Apr 2020.

20. Cohen J. Statistical power analysis for the behavioral sciences. Statistical power analysis for the behavioral sciences 2nd edition. New York: Lawrence Erlbaum Associates; 1988

21. Cronbach $\sqcup$. Coefficient alpha and the internal structure of tests. Psychometrika. 1951;16(3):297-334.

22. Paschou SA, Stamou M, Vuagnat H, Tentolouris N, Jude E. Pain management of chronic wounds: diabetic ulcers and beyond. Maturitas. 2018;117:17-21

23. Fagerdahl AM, Bergström G. Translation and validation of a wound-specific, quality-of-life instrument (the wound-QoL) in a Swedish population. Ostomy Wound Manag. 2018;64(5):40-6.

24. Augustin M, Conde Montero E, Zander N, Baade K, Herberger K, Debus ES, et al. Validity and feasibility of the wound-QoL questionnaire on health-related quality of life in chronic wounds. Wound Repair Regen. 2017;25:852-7.

25. Price PE, Fagervik-Morton H, Mudge EJ, Beele H, Ruiz JC, Nystrøm TH, et al. Dressing-related pain in patients with chronic wounds: an international patient perspective. Int Wound J. 2008:5(2):159-71.

26. Zander N, Demirel EB, Augustin M, Sommer R, Debus ES, Breuer P, et al Development and validation of the patient benefit index for peripheral arterial disease. Vasa - Eur J Vasc Med. 2018:47(3):219-26.

27. Barclay-Goddard R, King J, Dubouloz CJ, Schwartz CE. Building on transformative learning and response shift theory to investigate healthrelated quality of life changes over time in individuals with chronic health conditions and disability. Arch Phys Med Rehabil. 2012;93(2):214-20.

28. van Doorn LP, Sijberden JP, Brouwers JJWM, Hamming JF. Validation of the Dutch translation of the Cardiff wound impact schedule for evaluation of the health-related quality of life of patients with chronic wounds. Int Wound J. 2020;1-6. https://doi.org/10.1111/iwj.13388.

29. Wild D, Grove A, Martin M, Eremenco S, McElroy S, Verjee-Lorenz A, et al. Principles of good practice for the translation and cultural adaptation process for patient-reported outcomes (PRO) measures: report of the ISPOR task force for translation and cultural adaptation. Value Heal. 2005;8(2):94-104.

\section{Publisher's Note}

Springer Nature remains neutral with regard to jurisdictional claims in published maps and institutional affiliations.

\section{Ready to submit your research? Choose BMC and benefit from:}

- fast, convenient online submission

- thorough peer review by experienced researchers in your field

- rapid publication on acceptance

- support for research data, including large and complex data types

- gold Open Access which fosters wider collaboration and increased citations

- maximum visibility for your research: over $100 \mathrm{M}$ website views per year

At BMC, research is always in progress.

Learn more biomedcentral.com/submissions 